JMI Vol. 40 No. 2 Desember 2018

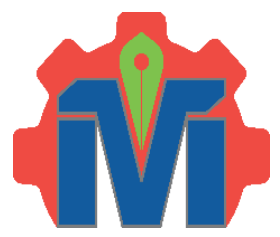

METAL INDONESIA

Journal homepage:

http://www.jurnalmetal.or.id/index.php/jmi

p-issn: $0126-3463$

e-issn : 2548-673X

\title{
RANCANG BANGUN ALAT UKUR KADAR KARET KERING PADA LATEKS BERBASIS TEKNOLOGI LIGHT SCATTERING
}

\author{
Deni Cahyadi, Irvando A. Damanik, Januar Arif Fatkhurrahman, Ikha R.J.S, Mardiana Agung \\ Balai Besar Logam dan Mesin, Jalan Sangkuriang No.12 Bandung 40135 \\ Email : dhifah_10@yahoo.com
}

\begin{abstract}
Abstrak
Kadar karet kering (KKK) menjadi salah satu ukuran kualitas lateks karena nilai ini menggambarkan besarnya kandungan air dalam lateks. Kadar karet kering (KKK) adalah kandungan padatan karet per satuan berat (\%). Pada pengolahan lembaran karet, nilai kadar karet kering (KKK) digunakan sebagai dasar penentuan jumlah kebutuhan air pada proses pengenceran lateks sampai diperoleh kadar karet baku (Kadar Karet Standar). Penentuan nilai kadar karet kering saat ini menggunakan metode gravimetri yang membutuhkan waktu sangat lama dan banyak menggunakan bahan kimia. Tujuan dilakukannya rancang bangun alat ukur kadar karet kering (KKK) berbasis Llight Scattering ini yaitu untuk memperoleh nilai kadar karet kering (KKK) dengan cepat. Alat ukur berbasis teknologi Llight Scattering dengan menggunakan microcontroller sebagai image processing merupakan alat ukur non destructive dan tanpa penggunaan bahan kimia dalam proses analisanya. Alat ini merujuk pada standar ISO 126 : 2005 tentang Method Of Test For Natural Rubber Latex, Determination Of Dry Rubber Content. Alat ini sudah berhasil diuji coba pada lapangan sebenarnya dan didapatkan hasil pengukuran lateks secara langsung dengan ketelitian lebih dari $90 \%$ dalam rentang pengukuran $15-30 \%$.
\end{abstract}

Kata kunci : Perancangan, Kadar Karet Kering ( KKK ), Lateks, Light Scattering

\section{Abstract}

Dry rubber content $(K K K)$ is one of latex quality measurement since this value represents the amount of water in the latex. Dry rubber content (KKK) is a rubber solid content per unit weight (\%). In rubber sheet processing, the value of dry rubber content $K K K$ is used as a basis for determining the amount of water needed in the latex dilution process until it is obtained the Raw Rubber Content (Standard Rubber Content). Determination of the value of dry rubbercontent at this time using the gravimetric method which takes a very long time and uses a lot of chemicals.The purpose of doing the design of dry rubber content measurement (KKK) based on Light Scattering is to obtain dry rubber content (KKK) values quickly. Measuring instrument based on Light Scattering technology using microcontroller as image processingis a non-destructive measurement utility and without the use of chemicals in the analysis process. This tool refers to the ISO 126: 2005 standard on Method of Test for Latex Natural Rubber, Determination of Dry Rubber Content. This device has been successfully tested on the actual environment and obtained the results of direct latex measurements with accuracy more than $90 \%$ within range measurement $15-30 \%$.

Keywords: design, dry rubber content (KKK), Latex, Light Scattering 


\section{PENDAHULUAN}

Karet alam sebagai salah satu komoditas utama di Indonesia merupakan komponen industry hilir yang tidak tergantikan oleh karet sintetis. Salah satu produk karet alam yang menjadi unggulan dan dikelola oleh perusahaan perkebunan negara di Indonesia adalah Ribbed Smoked Sheet (RSS). Proses produksi RSS sampai saat ini masih belum optimal dan menjadi perhatian khusus terutama pada pemakaian bahan kimia. Bahan kimia yang digunakan dalam proses produksi akan mengakibatkan buangan bahan kimia kelingkungan yang dapat mencemari dan menimbulkan efek negative terhadap lingkungan dan mempengaruhi kesehatan masyarakat.

Salah satu proses yang membutuhkan bahan kimia adalah penentuan Kadar Karet Kering (KKK) yang menggunakan asam formiat. Nilai KKK ini akan menentukan jumlah kebutuhan air yang dipakai pada tahapan proses selanjutnya (Kuriakose 2012). Tingginya nilai KKK menyatakan kandungan air dalam lateks semakin rendah (Sulasri, Malino, and Lapanporo 2014). Pada pengolahan karet lembaran, nilai kadar karet kering (KKK) digunakan sebagai dasar untuk menentukan jumlah kebutuhan air pada proses pengenceran lateks sampai diperoleh Kadar Karet Baku (Kadar Karet Standar). Proses pengenceran yang terlalu encer akan mengakibatkan koagulum (bekuan) yang dihasilkan terlalu lunak, sehingga mudah robek pada saat penggilingan. Sebaliknya jika koagulum terlalu keras, akan mengakibatkan pemakaian tenaga gilingan yang lebih besar dan memerlukan waktu pengeringan terlalu lama. Kondisi ini akan mempengaruhi mutu karet lembaran berdasarkan green book yang diterbitkan oleh International Rubber Quality and Packing Conference (IRQPC) (Indian Standard (IS) $153612003)$.

Analisa yang dilakukan di pabrik pengolahan karet lembaran pada perkebunan besar negara menggunakan metode gravimetri sederhana dan umumnya didasarkan pada pengalaman di lapangan. Dalam pengolahan karet RSS nilai kadar karet kering (KKK) perlu diperoleh secara cepat,yang digunakan sebagai dasar perhitungan kebutuhan air proses. Sejauh ini, proses untuk memperoleh kadar karet kering (KKK) kurang efektif, pasalnya untuk mengetahui KKK dengan alat laboratorium diperlukan waktu 12 jam. Kenyataannya, perkebunan besar menentukan KKK tidak sesuai standar danhanya berdasarkan selisih berat kering karet yang diperoleh secara manual sehingga memberikan hasil yang kurang akurat.

Teknologi kapasitansi dielektrik dan photoelectric merupakan inovasi penentuan kadar karet kering dalam lateks yang perlu dikembangkan dan disesuaikan dengan kebutuhan industri karet sheet, agar penentuan nilai KKK dapat dilakukan secara efektif dan akurat. Beberapa tahun terakhir penelitian analisa KKK mengalami perkembangan dan mengarah pada penggunaan teknologi photoelectric dan microcontroller sebagai inovasi penentuan kadar karet kering dalam lateks dengan hasil efektifitas dan keakuratan yang cukup tinggi (Julia Sari and Fatkhurahman 2015). Terobosan dengan memanfaatkan teknologi dalam penentuan KKK ini diharapkan mampu mengeliminasi permasalahan lingkungan khususnya terkait buangan bahan kimia.

Rancang bangun teknologi berupa alat ukur penentuan KKK dilakukan dengan mengkorelasikan antara metode standar baku terhadap analisis dimensi hamburan sinar (Light Scattering) partikel karet dari sinar merah laser dioda yang akan ditangkap oleh kamera. Berkas cahaya ini akan dianalisis FWHM (Full Width Half Maximum) menggunakan aplikasi persamaan mathematica 9.0 melalui computer yang kemudian dikorelasikan menjadi nilai KKK. FWHM merupakan jarak antara titik yang menggambarkan intensitas penuh sebuah kurva (Taylor et al. 2013). Semakin besar nilai KKK maka kandungan partikel karet dalam lateks semakin banyak, hal ini berbanding terbalik dengan pembacaan nilai FWHM yang semakin kecil dimana berkas cahaya yang ditangkap oleh kamera semakin redup, begitu sebaliknya. Nilai KKK dianalisis menggunakan metode standar ISO 126.

Setelah mendapatkan korelasi FWHM dengan nilai KKK yang dengan linearitas > 90\%. Maka dilakukan konstruksi dengan bantuan mikrokontroller sebagai image processing, sehingga memudahkan pengguna karena yang terbaca adalah langsung nilai KKK. Diharapkan dengan teknologi alat ukur ini mampu menggantikan analisa penentuan KKK di pabrik/ kebun yang lebih ramah lingkungan 
karena tidak menggunakan bahan kimia, lebih cepat, tepat dan mudah di dalam pengoperasiannya.

\section{METODOLOGI}

Rancang Bangun alat ukur kadar karet kering pada lateks ini dilakukan di workshop Balai Besar Logam dan Mesin Bandung. Metode rancang bangun yang digunakan merupakan metode kerekayasaan, dengan langkah pertama yaitu studi literatur dilanjutkan dengan mengidentifikasi komponen-komponen yang akan digunakan dalam pembuatan alat ukur KKK. Setelah semua komponen teridentifikasi, lalu dilakukan perancangan, pembuatan, perakitan dan instalasi/interface hingga pengujian alat dari segi keberfungsian setiap komponen.

Secara ringkas konstruksi alat ukur kadar karet kering merupakan rangkaian peralatan yang terdiri dari beberapa komponen elektronika yang dirangkai dengan microcontroller yaitu Raspberry pi3 menjadi pengendali utama.

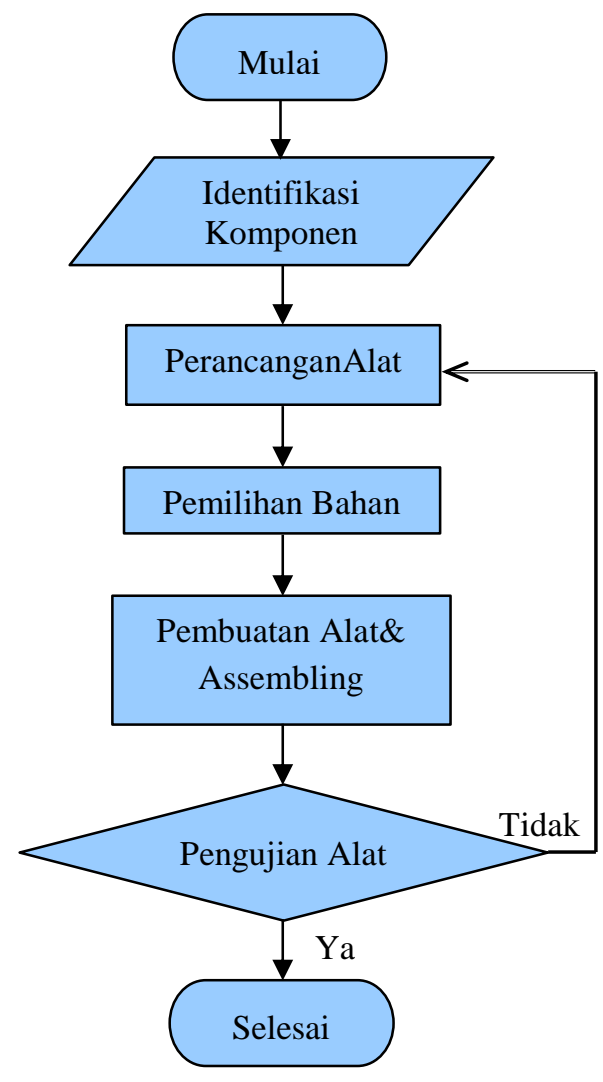

Gambar 1. Flowchart metodologi penelitian
Sistem kerjanya adalah sumber berkas cahaya, dalam hal ini laser merah dengan tegangan kerja 3,5 volt yang disusun paralel segaris dengan kuvet sebagai media lateks yang menjadi objek pengukuran dan image processing yaitu kamera sebagai penangkap berkas cahaya, seperti yang terlihat pada gambar 4 skema rangkaian peralatan.

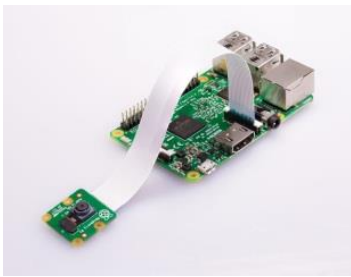

Gambar 2. Komponen raspberry pi3 dan kamera

Cahaya yang dipancarkan oleh laser akan mengenai permukaan cuvet yang sudah di isi lateks, sehingga cahaya yang tembus dari cairan lateks akan ditangkap pada kamera raspberry dan akan menghasilkan image. Mengingat sinar infra-red memiliki Panjang gelombang yang rendah, maka casing utama dipastikan tertutup rapat sehingga tidak ada berkas cahaya dari luar yang masuk ke dalam casing utama sehingga dapat mempengaruhi pembacaan kamera. Untuk memastikan tidak ada pengaruh cahaya luar, di dalam casing utama dipasangkan Light Dependent Resistor (LDR) sebagai light detector sebelum alat digunakan untuk menghitung nilai KKK.
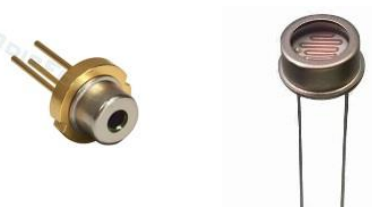

Gambar 3. Komponen laser diode dan LDR sensor

Selain itu alat ukur KKK di rancang dengan menggunakan material plat hollow aluminium dan dalamnya terdapat beberapa komponen pendukung sebagai tempat peletakan komponen utama alat. Pengaturan letak seluruh komponen baik yang utama maupun pendukung harus diperhatikan agar didapatkan rancangan terbaik dan alat berfungsi dengan sempurna. Komponen utama yang menjadi perhatian khusus adalah posisi laser yang berada tepat di depan cuvet harus segaris terhadap kamera 
untuk mendapatkan image yang maksimal sehingga pembacaan lebih baik. Jarak antara kamera, kuvet dan laser dapat diatur sedemikian rupa sehingga dapat diperoleh jarak tetap untuk mendapatkan hasil pengukuran Kadar Karet Kering yang optimal. Peralatan yang digunakan adalah jenis peralatan yang mudah ditemukan di pasaran. Rangkaian konstruksi peralatan dapat terlihat pada gambar 4 di bawah ini.

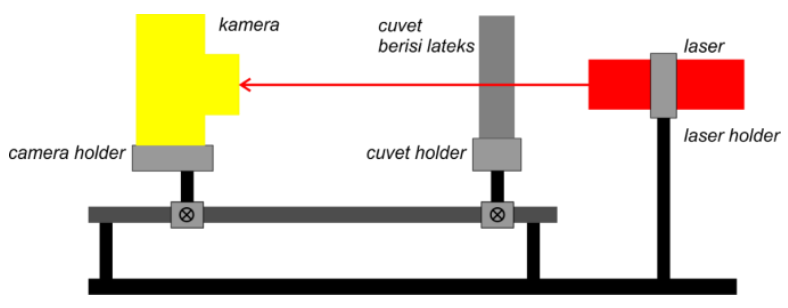

Gambar 4. Skema rangkaian peralatan

Dengan penambahan microcontroller sebagai unit utama yang dilengkapi dengan LCD sebagai media pembaca dan pengolah data berbasis Raspberry $\mathrm{Pi}$, aplikasi Mathematica terintegrasi dengan microcontroller, sehingga keselurahan pengolahan data dari mulai penangkapan berkas cahaya sampai menjadi nilai KKK tanpa melalui pengolahan data di komputer.

Komponen-komponen yang digunakan untuk membuat alat ukur kadar karet kering ini antara lain Laser, Image Processing, Kuvet, Micro controller, dan Light Dependentresistor (LDR).Pemilihan bahan dalam pembuatan alat ukur ini disesuaikan dengan fungsi alat tersebut, karena akan berpengaruh pada pengguna alat tersebut. Diantaranya adalah alat ukur harus rigid atau kokoh, berat alat harus disesuaikan agar pengguna merasa nyaman pada saat menggunakan alat.

Hasil trial error penentuan jarak laser, kuvet dan spesifikasi image processing nantinya menjadi variable tetap pada penelitian ini. Pembacaan nilai FWHM akan dikorelasikan dengan nilai KKK dengan korelasi linearitas minimal 90\%. Nilai KKK diperoleh dari hasil analisis menggunakan metode standar ISO 126: 2005 yang dianggap sebagai nilai acuan untuk verifikasi hasil pembacaan metode Light Scattering.

Alat ukur KKK berbasis Light Scattering ini dinyatakan layak dioperasikan bila hasil verifikasi dengan metode standar menghasilkan nilai simpangan maksimal 5\% dengan metode standar ISO 126.

\section{HASIL DAN PEMBAHASAN}

Tahapan kegiatan rancang bangun alat ukur kadar karet kering meliputi tahap perancangan, pembuatan komponen, perakitan dan pengujian.

\section{a. Perancangan}

Proses perancangan alat ukur KKK dilakukan dengan menggunakan software CAD dengan membuat 3D modeling dan 2D drawing guna memenuhi kebutuhan informasi dalam proses manufaktur. Selain itu gambar teknik ini dapat dijadikan sebagai dokumen teknik. Perancangan 3D modeling alat ukur KKK ini terdiri dari beberapa komponen utama antara lain:

- Casing Utama

- Support Laser

- Support Kamera

- Container Cuvet

Proses perancangan juga meliputi simulasi desain sehingga didapatkan kekuatan bahan yang akan digunakan dan jenis material yang akan cocok dipakai untuk alat ini. Setelah didapatkan desain yang optimal maka dibuatkan seluruh gambar yang mencakup komponenkomponen yang akan dibuat/dimanufaktur di workshop. Gambar Teknik ini sangat dibutuhkan untuk mendapatkan gambaran bentuk yang diinginkan serta ukuran-ukuran yang sudah ditentukan, sehingga saat proses assembly tidak akan ada masalah untukmasingmasing komponen.

Perancangan dimulai dengan membuat rancangan casing utama. Casing utama berfungsi sebagai rumah untuk menempatkan komponen-komponen pendukung alat ukur KKK. Dalam merancang casing utama, Bentuk dan dimensi sangat diperhitungkan karena dari segi bentuk harus disesuaikan dengan bentuk komponen pendukungnya dan dari segi artistik, bentuk casing utama ini harus mempunyai nilai jual. Hasil rancangan casing utama seperti terlihat pada gambar 5 . 


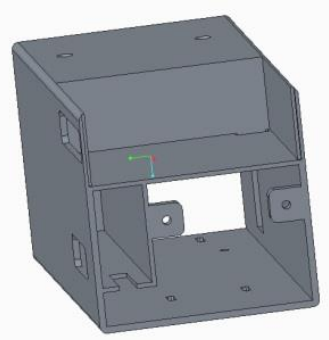

Gambar 5. Desain casing utama

Setelah mendapatkan hasil rancangan casing utama yang sesuai, dilakukanlah rancangan support (dudukan) untuk komponen laser dan kamera. Support laser dan kamera dirancang menyesuaikan dengan bentuk komponen laser dan kameranya, agar laser dan kamera dapat berdiri kokoh pada dudukannya. Support (dudukan) laser dan kamera ini diletakkan pada bagian bawah dalam casing utama. Hasil rancangan support (dudukan) laser dan kamera seperti terlihat pada gambar 6 .
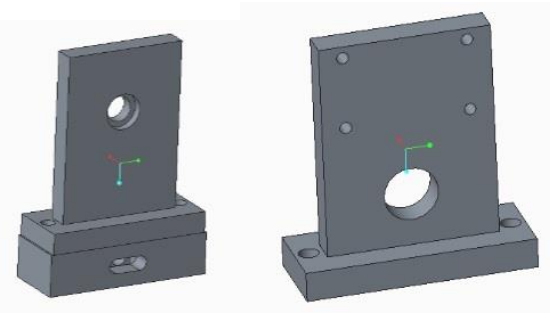

Gambar 6. Desain support kamera dan laser

Perancangan komponen container cuvet untuk dapat mengakomodasi cairan lateks. Cuvet adalah cawan untuk menampung cairan lateks yang akan diukur kadar karet keringnya, Sedangkan container cuvet ini berfungsi sebagai wadah cuvet. Container cuvet di desain dengan bagian bawah menyesuaikan dengan rel yang berada di dalam casing utama dan mampu bergerak secara sliding. Container cuvet juga didesain agar dapat di bongkar pasang, sehingga pemberian lateks ke cuvet lebih mudah dan tidak membutuhkan waktu yang lama untuk dilakukan pengukuran. Hasil rancangan sontainer cuvet seperti terlihat pada gambar 7 .

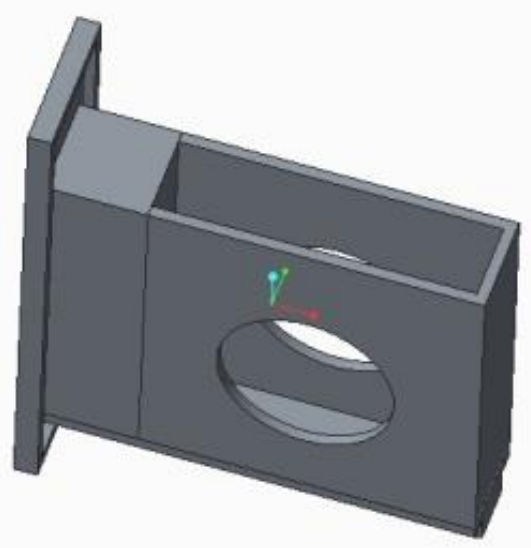

Gambar 7. Desain container cuvet

Setelah semua komponen di rancang, dilakukanlah proses perakitan atau assembly keseluruhan antara komponen satu dengan komponen yang lain. Hasil rancangan assembly alat ukur KKK seperti terlihat pada gambar 8 .
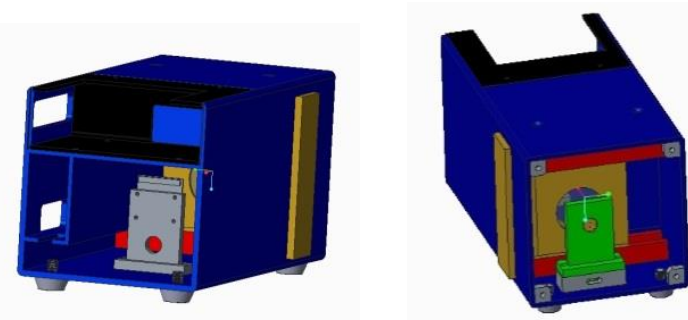

Gambar 8. Desain Assembly KKK

Pembuatan bill of material dari hasil rancangan alat ukur KKK yang telah dibuat. Pembuatan bill of material ini berfungsi untuk kebutuhan data informasi pengadaan material, baik dari segi jenis bahan maupun ukuran material yang akan digunakan. Bill of material alat ukur KKK seperti terlihat pada gambar 9.

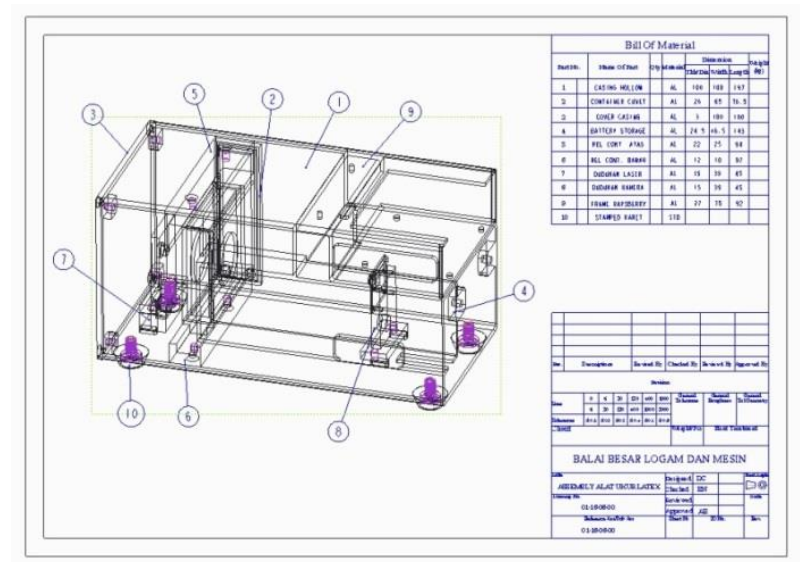

Gambar 9. Bill of material 
b. Tahap Pembuatan

Proses pembuatan komponen akan melalui beberapa tahapan mulai dari pemotongan material, penekukan, pengelasan, penghalusan, membuat lubang yang melibatkanbeberapamesinyaitumesin Bubut, Milling, Bor dan Las Aluminum. Material yang digunakan sebagian besar adalah aluminum karena memiliki berat yang ringan dan tahan karat, sehingga memudahkan para pengguna untuk membawa alat ukur pada saat melakukan pengukuran di perkebunan. Proses pembuatan komponen-komponen alat ukur KKK anta lain :

\section{Casing Utama}

Casing Utama adalah komponen utama dari pembuatan alat ukur KKK. Casing ini adalah sebagai tempat untuk komponen lain berada di dalamnya yaitu dudukan laser, dudukan kamera, dan tempat untuk penyimpanan baterry (power bank) serta tempat untuk microcontroller sebagai pengolah data. Casing utama terbuat dari plat hollow aluminium dengan dimensi $100 \mathrm{~mm} \times 100$ dengan panjang $200 \mathrm{~mm}$ dan tebal $5 \mathrm{~mm}$. Casing utama di bentuk sesuai dengan rancangan yang telah di tentukan, dan pembentukan casingnya di lakukan menggunakan proses machining dengan menggunakan mesin milling dan mesin las aluminium.
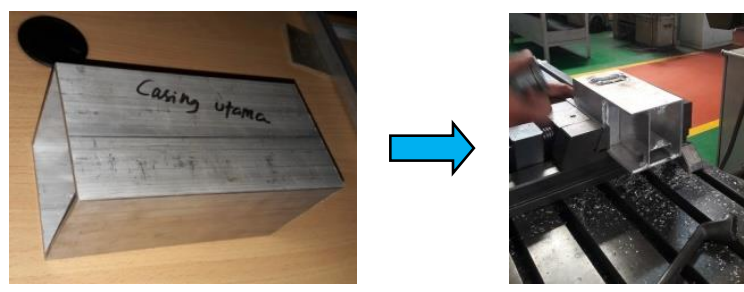

Gambar 10. Komponen casing utama

\section{Dudukan Laser dan Kamera}

Komponen dudukan laser dan kamera terbuat dari bahan aluminium dengan dimensi 42x39x15 mm. Komponen ini berfungsi sebagai penyanggah laser dan kamera di dalam casing utama, dimana komponen laser berfungsi sebagai sumber cahaya yang di tangkap oleh kamera sebagai image processing dan di olah oleh microcontroller.

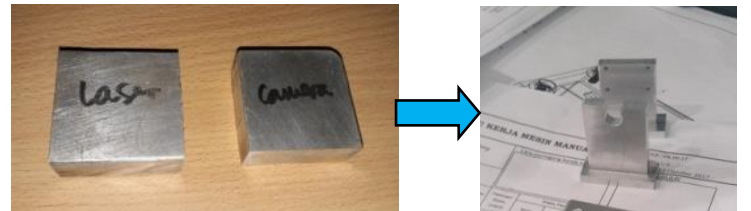

Gambar 11. Komponen dudukan laser dan kamera

\section{Casing Cuvet}

Komponen casing cuvet terbuat dari bahan aluminium dengan dimensi 86x76.5x26 $\mathrm{mm}$. Komponen ini dibuat melalui proses milling dan proses pengelasan pada bagian wadah cuvetnya.

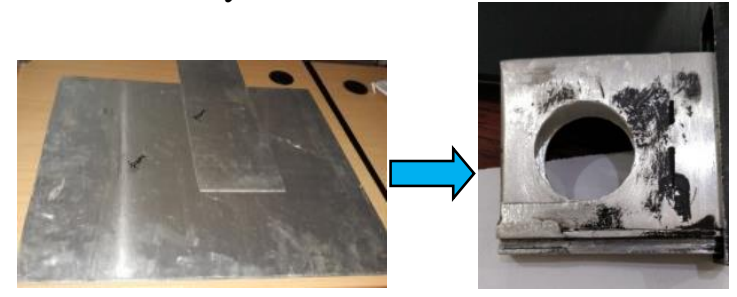

Gambar 12. Komponen container cuvet

\section{Casing Microcontroller (Raspberry)}

Komponen casing microcontroller pada alat ukur KKK ini terbuat dari bahan acrylic dengan dimensi $91.5 \times 81 \times 30 \mathrm{~mm}$. Pemilihan bahan acrylic ini agar mengurangi berat alat ukur tersebut dan juga untuk membuat tampilan exterior alat ukur KKK menjadi lebih artistik dan mempunyai nilai jual.

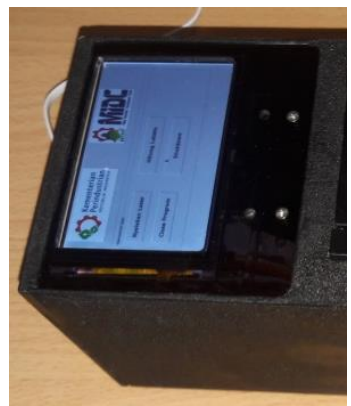

Gambar 13. Komponen casing microcontroller

\section{c. Tahap Perakitan}

Setelah seluruh komponen dipersiapkan, maka dilakukanlah proses perakitan sesuai dengan konsep rancangan alat ukur KKK yang telah dibuat. 


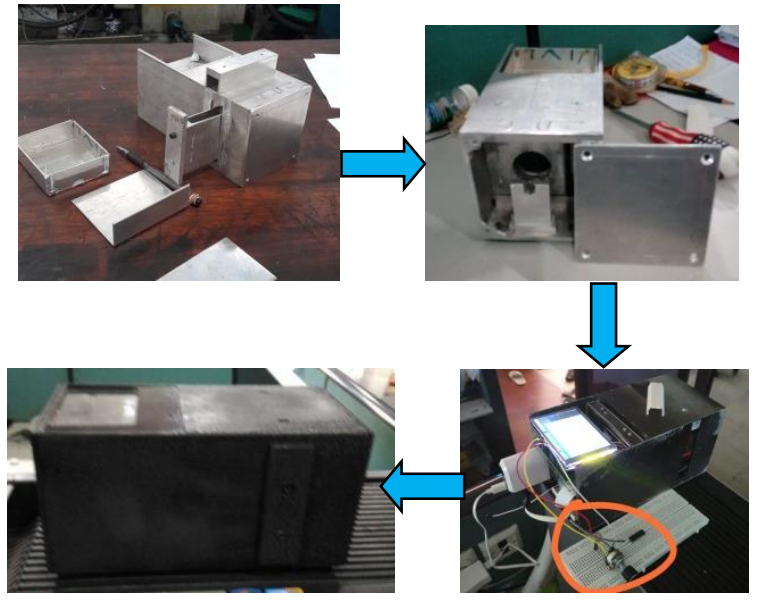

Gambar 14. Proses perakitan konstruksi alat ukur KKK

\section{d. Tahap Pengujian}

Setelah proses perakitan selesai dilakukan, maka dilakukanlah proses pengujian. Masingmasing komponen kemudian diuji fungsi secara keseluruhan, sehingga alat ukur KKK dapat digunakan untuk mengukur kadar karet kering. Dalam hal ini semua pengujian keberfungsian komponen dilakukan melalui layer LCD yang sudah dipasang dan menggunakan software phyton. Pengujian pertama yang dilakukan yaitu uji nyala laser yang telah di sambungkan ke microcontroller yaitu raspberry. Tahapan ini berfungsi untuk mengetahui bahwa laser sudah bisa di on-off kan melalui pin Raspberry pi yang dikontrol melalui LCD.

Dilakukan pengujian uji nyala kamera yang sama halnya dengan laser dikontrol dari LCD. Tahapan ini bertujuan untuk mendapatkan image yang ada di depan kamera itu sendiri dan setelah berhasil maka akan digunakan untuk menangkap berkas cahaya merah yang dipancarkan oleh laser. Tahapan ini merupakan salah satu bagian penting karena data tangkapan kamera adalah data awal dalam perhitungan nilai KKK.

Uji coba alat ukur dengan melakukan pengukuran menggunakan cairan lateks yang diambil beberapa sampel dari beberapa kebun di PT. Perkebunan Nusantara IX. Ujicoba dalam hal ini merupakan pembandingan nilai uji KKK pada metode ISO 126 sebagai metode standar pengujian KKK dibandingkan dengan KKK hasil analisis berbasis Light Scattering. Seperti terlihat pada tabel di bawah ini.

Tabel 1. Perbandingan analisis KKK pada metode ISO 126 dan light scattering

\begin{tabular}{|c|c|c|}
\hline \multirow{2}{*}{ Sampel } & \multicolumn{2}{|c|}{ Analisis KKK (\%) } \\
\cline { 2 - 3 } & Metode ISO 126 & Light Scattering \\
\hline 1 & 24,39 & 16,00 \\
\hline 2 & 30,19 & 27,23 \\
\hline 3 & 27,54 & 21,24 \\
\hline 4 & 31,98 & 27,98 \\
\hline
\end{tabular}

Terlihat pada hasil analisis metode ISO 126 terhadap metode berbasis Light Scattering mempunyai perbedaan nilai yang signifikan, namun secara proporsional, tingkatan nilai pada kedua metode tersebut cukup gradual, sehingga dilakukan analisis least square pada kedua data tersebut, seperti terlihat pada gambar di bawah ini.

Least Square Analysis Nilai KKK

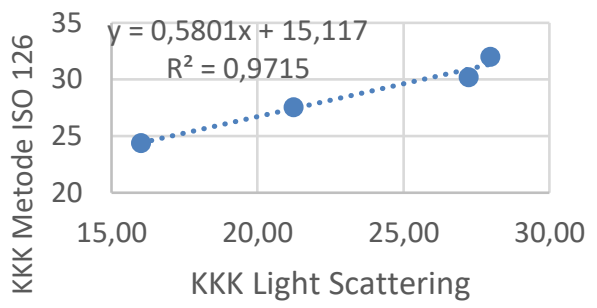

Gambar 15. Least square analysis nilai KKK

Pada least square analisis tersebut diperoleh persamaan least square $\mathrm{y}=0,5801 \mathrm{x}+$ 15,117 dengan nilai linieritas $\mathrm{R}$ sebesar 0,986. Persamaan least square tersebut kemudian dikorelasikan terhadap nilai bacaan KKK pada metode Light Scattering dan diperoleh data sebagai berikut.

Tabel 2. Beda nilai KKK setelah analisis least square

\begin{tabular}{|c|c|c|c|c|}
\hline \multirow{4}{*}{ Sampel } & \multicolumn{3}{|c|}{ Analisis KKK (\%) } & $\begin{array}{c}\text { Beda } \\
\text { Nilai } \\
\text { KKK }\end{array}$ \\
\cline { 2 - 5 } & $\begin{array}{c}\text { Metode } \\
\text { ISO } \\
126\end{array}$ & Colorimetri & $\begin{array}{c}\text { Least } \\
\text { Square }\end{array}$ & \\
\hline 1 & 24,39 & 16,00 & 24,40 & 0,01 \\
\hline 2 & 30,19 & 27,23 & 30,91 & 0,72 \\
\hline 3 & 27,54 & 21,24 & 27,44 & $-0,10$ \\
\hline 4 & 31,98 & 27,98 & 31,35 & $-0,63$ \\
\hline
\end{tabular}




\section{KESIMPULAN}

Rancang bangun Alat ukur KKK telah berhasil di uji coba di lapangan dan mendapatkan nilai KKK secara cepat dibandingkan dengan cara konvensional dengan ketelitian diatas $90 \%$, serta alat sangat mudah dalam hal penggunaan dan pemindahan. Range pengukuran nilai KKK pada lateks adalah 15$30 \%$. Verifikasi nilai KKK didasarkan pada verifikasi hasil peralatan terhadap nilai KKK sesuai ISO 126 : 2005 yang sudah di least square.

\section{SARAN}

Diperlukan lebih banyak database rentang nilai KKK pada lateks untuk mendapatkan hasil verifikasi dengan linieritas dan kualitas yang lebih baik.

\section{UCAPAN TERIMA KASIH}

Pada kesempatan ini penulis berterima kasih kepada BBLM yang telah memberikan kesempatan mendukung kegiatan rancang bangun ini serta Puslitbang TIKI-BPPI sebagai pemberi bantuan dana dalam hal operasional dan bahan.

\section{DAFTAR PUSTAKA}

Indian Standard (IS) 15361. 2003. India: Raw Natural Rubber - Ribbed Smoked Sheets (RSS) - Guidelines [PCD 13: Rubber and Rubber Products].

Julia Sari, Ikha Rasti, and Januar Arif Fatkhurahman. 2015. "Review of Determining Dry Rubber Content.” In Prosiding Seminar Nasional Kulit, Karet, Dan Plastik Ke-4, 169-80. Yogyakarta: Balai Besar Kulit, Karet dan Plastik.

Kuriakose, Baby. 2012. "Primary Processing." In Natural Rubber: Biology, Cultivation and Technology, edited by M.R. Sethuraj and N.M Mathew, 102-65. Amsterdam: Elsevier Science. https://doi.org/doi:10.1201/b1147919\r10.1201/b11479-19.

Sulasri, Mariana B Malino, and Boni P Lapanporo. 2014. "Penentuan Kadar Kering Karet ( K3 ) Dan Pengukuran Konstanta Dielektrik Lateks." Prisma Fisika II (1):11-14.

Taylor, P., N. A. George, A. Peethan, and M. Vijayan. 2013. "Nondestructive Testing and Evaluation A Simple Optical Sensor for the Measurement of Dry Rubber Content in Natural Rubber Latex." Nondestructive Testing and Evaluation $37-41$. http://doi.org/10.1080/10589759.2013.785 545. 